\title{
Prediction of Length of Hospital Stay and Immediate Outcome of Children Suffering From Bronchiolitis on the Bases of Associated Risk Factors
}

\author{
Bithi Debnath $^{1}$, Sajani Islam ${ }^{2}$, Nazmul Haque ${ }^{3}$
}

\begin{abstract}
${ }^{1}$ Assistant Professor, Department of Pediatric Neurology, National Institute of Neurosciences and Hospital, Dhaka, Bangladesh; ${ }^{2}$ Assistant Professor, Department of Pediatrics, Shaheed Suhrawardy Medical College and Hospital, Dhaka, Bangladesh; ${ }^{3}$ Assistant Professor, Dept. of Pediatric Neurology, National Institute of Neurosciences and Hospital, Dhaka, Bangladesh
\end{abstract}

[Received: 12 July 2020; Accepted: 30 August 2020; Published: 1 December 2020]

\begin{abstract}
Background: Bronchiolitis is the most common reason for hospitalization among children younger than 2 years. Objective: The aim of the study was to assess the possibility that the associated risk factors in children suffering from bronchiolitis could predict the length of hospital stay and also to observe the immediate outcome. Methodology: This prospective study was conducted in a district hospital of Bangladesh in a period of two years from January 2011 to December 2012. Patients aged 2 years or less fulfilling inclusion criteria for bronchiolitis and required admission were enrolled in this study. Patients having comorbidities and who were discharged before fulfilling the study criteria for discharge were excluded from the study. Treatment was given according to National Guidelines for the Management of Bronchiolitis. All demographic, clinical and laboratory data were recorded in a prefixed questionnaire and analyzed. Results: Among 100 patients, $60 \%$ cases were hospitalized for 4 days or more. Mean duration of hospital stay was $4.37 \pm 1.93$ days. Patients of male sex (67\%), younger than 6 months of age (71\%), preterm birth $(21 \%)$, weight-for-age was either $\geq 2$ SD $(60 \%)$ or $\leq 3 \mathrm{SD}(23 \%)$ were hospitalized for longer duration. Length of hospitalization was also increased in patients with family history of asthma (37\%), smoking $(75 \%)$, using wood-burning stoves for cooking $(89 \%)$ and no previous history of respiratory distress (81\%). Exclusively breastfed infants (41\%) stayed hospital for shorter duration than those who fed partially (53\%) or not at all (6\%). All patients were improved in this case series (100\%). Conclusion: Bronchiolitis patients having male sex, age less than 6 months, preterm born, partially breast fed, family history of asthma, exposure to smoking and wood-burning stoves were deduced to be significant risk factors for prolongation of length of hospitalization. Further research is needed to determine how these risk factors contribute to the development of the disease and prolong the length of hospital stay. [Bangladesh Journal of Infectious Diseases, December 2020;7(2):67-71]
\end{abstract}

Keywords: Bronchiolitis, risk factors, hospital stay, outcome.

Correspondence: Dr. Bithi Debnath, Assistant Professor, Dept. of Pediatric Neurology, National Institute of Neurosciences and Hospital, Sher-e-Bangla Nagar, Dhaka-1207, Bangladesh; Cell no.: +8801711236107; Email: bithidebnath@ gmail.com

Conflict of interest: There is no conflict of interest to any of the authors of this article.

Funding agency: The study was not funded by any authority.

Contribution to authors: BD was involved in study designing, data collection, compiling, data analysis and manuscript writing. Rests were involved in overall supervision.

How to cite this article: Debnath B, Islam S, Haque N. Prediction of Length of Hospital Stay and Immediate Outcome of Children Suffering From Bronchiolitis on the Bases of Associated Risk Factors. Bangladesh J Infect Dis 2020;7(2):67-71

Copyright: (02020. Debnath et al. Published by Bangladesh Journal of Infectious Diseases. This article is published under the Creative Commons CC BY-NC License (https://creativecommons.org/licenses/by-nc/4.0/). This license permits use, distribution and reproduction in any medium, provided the original work is properly cited, and is not used for commercial purposes. 


\section{Introduction}

Acute bronchiolitis, a viral infection of the lower respiratory tract, is one of the most substantial health burdens for infants and young children worldwide. It is the leading cause of hospital admission for respiratory disease among infants $<1$ year of age ${ }^{1}$. It commonly occurs in the first 2 years of life, and diagnosis is based on clinical signs ${ }^{2}$. Each year 150 million new cases of bronchiolitis are reported worldwide, and 2.0 to $3.0 \%$ of affected infants require hospitalization ${ }^{3}$. Mortality rate is approximately $2 / 100,000$ infants and higher in developing than developed countries ${ }^{4}$. Respiratory syncytial virus (RSV) remains the most commonly identified causative agent. Other viruses are also implicated in the etiology of bronchiolitis ${ }^{5}$.

Although RSV infection is known as a risk factor for severe bronchiolitis ${ }^{6}$, other risk factors have also been associated. Environmental exposure of children or their mothers to allergens, cigarette smoke, overcrowded living conditions can contribute to the severity of bronchiolitis ${ }^{7-9}$. The host-related factors are male sex, premature birth, low birth weight, or short birth length. ${ }^{10}$ Other associated risk factors include the lack of breastfeeding, maternal age, inadequate prenatal care, incomplete vaccination history, and a family history of asthma ${ }^{10-14}$.

Treatment of bronchiolitis is symptomatic and focuses on the maintenance of hydration, oxygenation and antipyresis ${ }^{15,16}$. Many infants hospitalized because of respiratory illness due to respiratory syncytial virus infection improve quickly and are discharged within 24 to 72 hours of admission, whereas some infants require longer hospitalization $^{17,18}$. Length of hospitalization in some countries averages twice that of others ${ }^{19}$. This variable pattern suggests a lack of consensus among clinicians as to best practices. The aim of this study was to estimate the associations with established risk factors on the length of hospital stay and also to predict the immediate outcome in children suffering from bronchiolitis treated in an inpatient department in a district hospital in Bangladesh.

\section{Methodology}

This prospective study was carried out in inpatient pediatric unit of 250 bed general hospital, Meherpur, Bangladesh from January 2011 to December 2012. Diagnosis of bronchiolitis was made if the child is upto 2 years of age having respiratory distress associated with wheeze preceded by runny nose, cough with or without lowgrade fever ${ }^{20}$. Admitted patients aged 2 years or less fulfilling inclusion criteria for bronchiolitis were enrolled in this study. Detailed history including the possible risk factors, the management and daily follow-up on the ward and the outcome at discharge were documented through a structured questionnaire.

Patients having congenital heart disease, chronic lung disease, immunocompromised state and who were discharged on request before fulfilling the study criteria for discharge or referred to higher centers for better management were excluded from the study. Treatment as well as supportive therapy was given according to National Guidelines for the Management of Bronchiolitis ${ }^{20}$. Patients were discharged when there were no requirement of supplemental oxygen, return of social smile and feed adequately. Their hospital stay was recorded in a prefixed questionnaire and analyzed. 7 patients were referred to higher center, 5 patients discharged on request before fulfilling discharge criteria. Finally 100 patients were analyzed.

All data were entered in SPSS 16 for Windows statistical software and analyzed. A $p$ value of $(\leq 0.05$ indicated statistical significance. Weight for age of the patients were calculated by using WHO Anthro 2005 software. A written consent for enrollment, treatment and follow up was taken from every parents. The study was given ethical clearance from the ethical review committee (ERC) of the hospital.

\section{Results}

A total number of 112 admitted patients of bronchiolitis were initially enrolled in this study. Patients who were discharged on request before fulfilling the study criteria for discharge, referred to higher centers for better support or absconded were excluded from the study. In this series, no patient was expired.

All patients were improved completely and finally relevant data of 100 patients were analyzed. In this study, more than half of the patients $(53 \%)$ belonged to the age group 3 to 6 months, and most $(67.0 \%)$ of the patients were male. Mean duration of hospital stay was 4.37 days; $60 \%$ of the patients stayed in the hospital for a period of 4 days or more. Mean duration of illness before admission was 5.47 days (Table 1). 
Table 1: Baseline Characteristics of Study Population $(\mathbf{n}=100)$

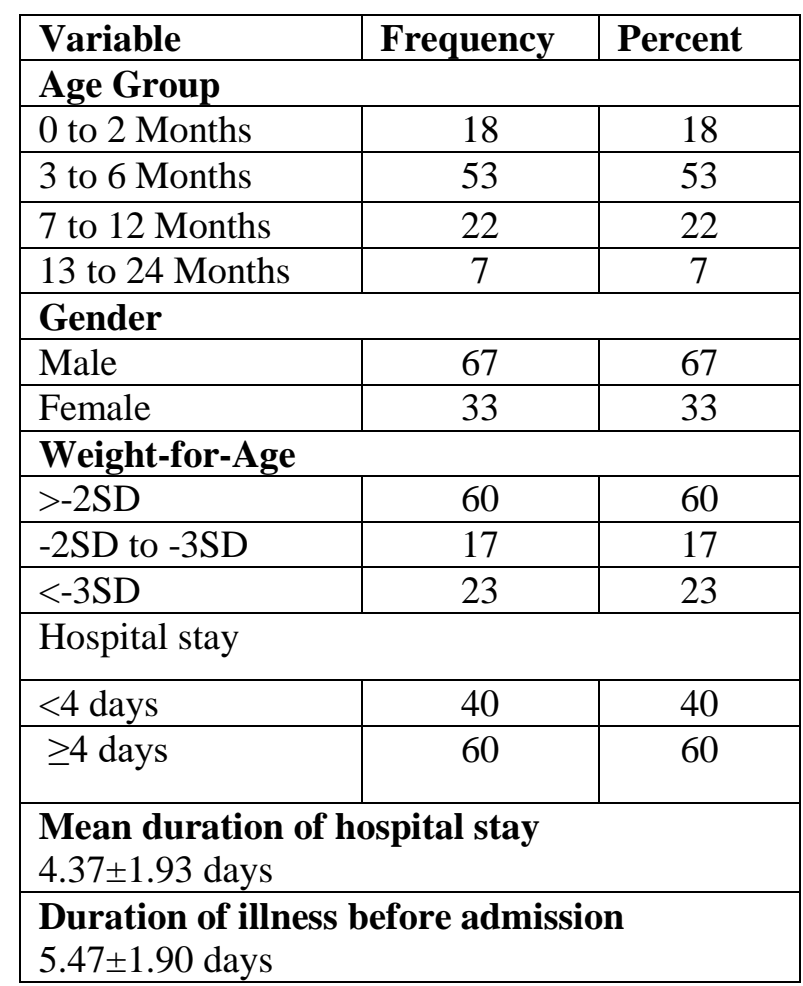

In this series, only $16 \%$ of the patients had given the history of similar type of illness in another sibling. Family history of asthma was found in one third cases. Most of the patients came of poor socioeconomic conditions and many of them (55\%) living in a room accommodating four or more persons. In many of the cases $(75 \%)$, there were a smoker among the family members. $89 \%$ children were living in households using wood-burning stoves. More than half of (59\%) affected children were either partially or not breastfed at all. Pervious history of respiratory illness were present in only 19 cases. Most of the patients (82\%) received medication before admission (Table 2).

Male patients needed to be hospitalized for longer period and this variation was more marked in the age group of 3-6 months. Children born preterm were hospitalized for longer duration when compared with term born.
Table 2: Associated Risk Factors in Study Population $(\mathrm{n}=100)$

\begin{tabular}{|c|c|c|}
\hline Variables & Frequency & Percent \\
\hline \multicolumn{3}{|l|}{ Gestational age } \\
\hline Term & 79 & 79 \\
\hline Preterm & 21 & 21 \\
\hline \multicolumn{3}{|c|}{ Family income (month) } \\
\hline$<5000 \mathrm{BDT}$ & 60 & 60 \\
\hline 5000-10,000 BDT & 35 & 35 \\
\hline$<10,000 \mathrm{BDT}$ & 5 & 5 \\
\hline \multicolumn{3}{|c|}{ Family members living in one room } \\
\hline 3 or less & 45 & 45 \\
\hline 4 or more & 55 & 55 \\
\hline \multicolumn{3}{|l|}{ Cooking } \\
\hline Wood-burning stove & 89 & 89 \\
\hline Gas & 8 & 8 \\
\hline Electric heater & 2 & 2 \\
\hline Others & 1 & 1 \\
\hline \multicolumn{3}{|l|}{ Breast Feeding } \\
\hline - Exclusive & 41 & 41 \\
\hline - $\quad$ Partial & 53 & 53 \\
\hline - Not at all & 6 & 6 \\
\hline $\begin{array}{l}\mathrm{H} / \mathrm{O} \text { Bronchiolitis in } \\
\text { sibs }\end{array}$ & 16 & 16 \\
\hline Family H/O asthma & 37 & 37 \\
\hline Smoking in the family & 75 & 75 \\
\hline $\begin{array}{l}\text { Previous } \mathrm{H} / \mathrm{O} \\
\text { respiratory distress }\end{array}$ & 19 & 19 \\
\hline
\end{tabular}

Children whose weight-for-age was either $\geq 2 \mathrm{SD}$ or $\leq 3$ SD stayed in the hospital for $\geq 4$ days; this statistical significant phenomenon was not observed in the -2SD to -3SD group. Hospital stay was significantly higher ( $p 0.001)$ when there was a history of smoking in the family and use of wood burning stove. Partial breast feeding was a significant factor for longer hospital stay than exclusive breastfeeding. Those who had no previous history of respiratory illness hospitalized for longer duration and this was more marked in 36 months age group. Similar results were also obtained when family history of asthma was considered (Table 3).

Table 3: Length of Hospital Stay On the Bases of Associated Risk Factors (n=100)

\begin{tabular}{|l|c|c|c|}
\hline Variables & $\begin{array}{c}\text { Hospitalized for }<\mathbf{4} \\
\text { Days }(\mathbf{n = 1 0 0})\end{array}$ & $\begin{array}{c}\text { Hospitalized for } \geq \mathbf{4} \\
\text { Days }(\mathbf{n}=\mathbf{1 0 0})\end{array}$ & P value \\
\hline Male & 23 & 44 & $<0.001$ \\
\hline Female & 17 & 16 & 0.134 \\
\hline Preterm & 8 & 13 & 0.045 \\
\hline Weight-for-age & \multicolumn{4}{|l}{} \\
\hline
\end{tabular}




\begin{tabular}{|l|c|c|c|}
\hline$\geq 2$ SD & 27 & 33 & 0.003 \\
\hline-2 SD to -3SD & 7 & 10 & 0.235 \\
\hline$\leq 3$ SD & 6 & 17 & 0.027 \\
\hline Smoking & 29 & 46 & 0.001 \\
\hline Wood burning stove & 35 & 54 & 0.001 \\
\hline Exclusive breast feeding & 14 & 27 & 0.058 \\
\hline Partial breast feeding & 22 & 31 & 0.004 \\
\hline No H/O previous respiratory illness & 32 & 49 & $<0.001$ \\
\hline Family H/O asthma & 14 & 23 & 0.001 \\
\hline
\end{tabular}

\section{Discussion}

Many infants are hospitalized due to bronchiolitis improve quickly and are discharged within 24-72 hours of admission, whereas some infants require longer hospitalization. This study was undertaken to determine whether the associated risk factors might cause patients with bronchiolitis to be hospitalized for longer duration. This study also showed the immediate outcome of admitted patients with bronchiolitis.

Children with bronchiolitis are admitted in the hospital for supportive care, not for specific therapies. Although most children with bronchiolitis have a mild course, some children have severe respiratory distress requiring admission in ICU or may die occasionally due to respiratory failure.

In this study, most of the patients were male, the median age of the children was 3.87 months and $71 \%$ were below 6 months of age. Most of the babies were born term. Majority of the parents were poor. In 55\% cases the number of family members in one room were four or more. These findings are consistent with a previous study by Kabir et $\mathrm{al}^{21}$.

In this prospective study, the mean duration of hospital stay was 4.37 days. It is observed that male patients had a greater likelihood of being hospitalized than female patients and also stayed for a longer duration. Patients less than 6 months of age and born preterm were more likely to have severe disease course and longer duration of hospital stay. It is consistent with some previous studies ${ }^{17,21-24}$. A study conducted by Shay et $\mathrm{al}^{22}$ showed that mean duration of hospitalization was 3 days. But they found no relationship between the length of hospitalization with age and sex of the patient. Other potentially important variables that increase the length of hospitalization include passive smoking in the family, using wood-burning stoves, partial breast feeding, family history of asthma and no previous history of respiratory illness. Many studies conducted previously suggested that above factors were associated with the development of severe bronchiolitis $^{25-28}$. But they did not correlate that parameters with the hospital stay. In this study, it is observed that children whose weight for age were either >-2SD or <-3SD hospitalized for longer duration. No previous data was found in this regard.

The treatment modalities of bronchiolitis are mainly supportive. All patients in this series were given nebulization. IV fluid was required in cases with severe respiratory distress or where there was chance of aspiration with oral feeding. Steroids were given cautiously when there was severe respiratory distress. Oxygen supplementation was given where indicated. All patients were improved in this case series. Recovery period was rapid in the parameters of female, who were born at term, weight for age $2 \mathrm{SD}$ to $-3 \mathrm{SD}$, exclusive breast feeding and previous respiratory illness.

There were several potential limitations in this study. It was a small scale prospective study. Most of the patients in this study came from lower socioeconomic condition. So the socio-demographic profile does not reflect the whole society. We had to refer some patients who were initially enrolled in this study for pediatric intensive care facilities.

\section{Conclusion}

Male sex, preterm baby, family history of asthma, smoking, household cooking by wood-burning stove and partial or no breastfeeding at all are not only the risk factors for Bronchiolitis but also they are implicated in prolonged hospitalization. In most instances, this association is more marked in younger age group (below 6 months) of patients. On the other hand, history suggestive of previous respiratory illness is associated with shortened duration of hospitalization. 


\section{References}

1. Hall CB, Weinberg GA, Iwane MK, et al. The burden of respiratory syncytial virus infection in young children. N Engl J Med 2009;360:588- 98.

2. Kirolos A, Manti S, Blacow R, Tse G, Wilson T, Lister M, Cunningham S, Campbell A, Nair H, Reeves RM, Fernandes RM. A Systematic Review of Clinical Practice Guidelines for the Diagnosis and Management of Bronchiolitis. The Journal of Infectious Diseases. 2019 Aug14.

3. Nenna R, Cutrera R, Frassanito A, Alessandroni C, Nicolai A, Cangiano G, et al. Modifiable risk factors associated with Bronchiolitis. Ther Adv Respir Dis.2017;1-9

4. Holman RC, Shay DK, Curns AT, Lingappa JR, Anderson LJ. Risk factors for Bronchiolitis-associated death among infants in the United States. Pediatr Infect Dis J 2003;22:483-90.

5. Xiao Q, Zheng S, Zhou L, et al. Impact of human rhinovirus types and viral load on the severity of illness in hospitalized children with lower respiratory tract infections. Pediatr Infect Dis J 2015;34(11):1187-1192

6. García CG, Bhire R, Soriano A, et al. Risk factors in children hospitalized with RSV bronchiolitis versus non-RSV bronchiolitis. Pediatrics 2010;126:1453-60

7. Karr C, Lumley T, Shepherd K, et al. A case-crossover study of wintertime ambient air pollution and infant bronchiolitis. Environ Health Perspect 2006;114:277-81

8. Karr C, Lumley T, Schreuder A, et al. Effects of subchronic and chronexposure to ambient air pollutants on infant bronchiolitis. Am J Epidemiol 2007;165:553-60

9. Rossi GA, Medici MC, Arcangeletti MC, et al. Risk factors for severe RSV-induced lower respiratory tract infection over four consecutive epidemics. Eur J Pediatr 2007;166:1267-72

10. Cilla G, Sarasua A,Montes M, et al. Risk factors for hospitalization due to respiratory syncytial virus infection among infants in the Basque country, Spain. Epidemiol Infect 2005;134:506-13.

11. Carroll KN, Gebretsadik T, Griffin MR, et al. Maternal asthma and maternal smoking are associated with increased risk of bronchiolitis during infancy. Pediatrics 2007;119:1104-12.

12. Koehoorn M, Karr CJ, Demers PA, et al. Descriptive epidemiological features of bronchiolitis in a population-base cohort. Pediatrics 2008;122:1196-203.

13. Vidaurreta SM, Marcone DN, Ellis A, et al. Infeccion respiratoria aguda viral en niños menores de 5 años. Estudio epidemiológico en dos centros de Buenos Aires, Argentina. Arch Argent Pediatr 2011;109:296-304

14. Veeranki SP, Gebretsadik T, Dorris SL, et al. Association of folic acid supplementation during pregnancy and infant bronchiolitis. Am J Epidemiol 2014;179:938-46

15. Tomažič J, Strle F. Infekcijske bolezni. Vol. 1. Ljubljana:
Združenje za infektologijo, Slovensko zdravniško društvo Ljubljana 2014/2015

16. Ingelfinger JR, Meissner HC. Viral bronchiolitis in children. N Engl J Med. 2016; 374(1):62-72.

17. McMillan JA, Tristram DA, Weiner LB, Higgins AP, Sandstrom C, Brandon R. Prediction of the duration of hospitalization in patients with respiratory syncytial virus infection: use of clinical parameters. Pediatrics. 1988 Jan $1 ; 81(1): 22-6$

18. Cunningham S, Rodriguez A, Adams T, et al.; Bronchiolitis of Infancy Discharge Study (BIDS) group. Oxygen saturation targets in infants with bronchiolitis (BIDS): a double-blind, randomised, equivalence trial. Lancet $2015 ; 386: 1041-8$.

19. Behrendt CE, Decker MD, Burch DJ, Watson PH. International variation in the management of infants hospitalized with respiratory syncytial virus. International RSV Study group.Eur J Pediatr.1998;157:215-220.

20. Bronchiolitis. In $3^{\text {rd }}$ edition. National guidelines Asthma Bronchiolitis COPD. Dhaka, Bangladesh: Asthma association Bangladesh, 2005: 137-143.

21. Kabir ML, Haq N, Hoque M, Ahmed F, Amin R, Hossain A, et al. Evaluation of hospitalized infants and young children with bronchiolitis-a multi centre study. Mymensingh medical journal: MMJ. 2003;12(2):128-33

22. Shay DK, Holman RC, Newman RD, Liu LL, Stout JW, Anderson LJ. Bronchiolitis-associated hospitalizations among US children, 1980-1996. Jama. 1999 Oct 20;282(15):1440-6

23. Wang EE, Law BJ, Stephens D, Pediatric Investigators Collaborative Network on Infections in Canada (PICNIC). Prospective study of risk factors and outcomes in patients hospitalized with respiratory syncytial viral lower respiratory tract infection. J Pediatr. 1995;126(2):212-9

24. Chan PW, Lok FY, Khatijah SB. Risk factors for hypoxemia and respiratory failure in respiratory syncytial virus bronchiolitis. Southeast Asian journal of tropical medicine and public health. 2002 Dec 22;33(4):806-10

25. Simoes EA. Environmental and demographic risk factors for respiratory syncytial virus lower respiratory tract disease. The Journal of pediatrics. 2003 Nov 1;143(5):118-26

26. Nielsen HE, Siersma V, Andersen S, Gahrn-Hansen B, Mordhorst CH, Nørgaard-Pedersen B, et al. Respiratory syncytial virus infection — risk factors for hospital admission: a case-control study. Acta Paediatrica. 2003 Nov;92(11):1314-21 27. Holberg CJ, Wright AL, Martinez FD, Ray CG, Taussing LM, Lebowitz MD, Group Health Medical Associates. Risk factors for respiratory syncytial virus-associated lower respiratory illnesses in the first year of life. American Journal of Epidemiology. 1991;133(11):1135-5

28. Carlsen KH, Larsen S, Bjerve Ø, Leegaard J. Acute bronchiolitis: predisposing factors and characterization of infants at risk. Pediatric Pulmonology. 1987;3(3):153-60 